\title{
Chapter 1: The Rise of Networks and Network Working
}

"Networks have become the predominant organizational form of every domain of human activity" Castells 2011

We live in a highly networked world. Social networks are integral to how our children and increasingly we ourselves live our lives. We can ask questions of people all round the world and get answers and ideas almost immediately. Whilst hierarchical organisational forms have delivered predictability and order, in our newly connected, highly dynamic environment where our social networks are part of our identity, and where the solutions of the past don't appear to be delivering for an even more complex future, networks as a way of organising are becoming a natural part of organisational life.

In health care it seems to be the coming together of personal preference, people's experience of health services that transcend organisational boundaries, and a mixture of policy intent and mishap, that has shaped the sense that networks are becoming a new, emergent 'norm' for learning and working together.

Networks, however, are unlike the traditional model of command and control that underpins the experience of most people who work in the NHS. The NHS, whilst varied in how it operates locally in terms of focus, is a very top down, hierarchial structure, unused to rapid innovation. In fact the distrust of professionals, arising from the Thatcher era, has in effect killed off the natural orientation of professionals towards learning and change through networks. This, combined with the dominance of performance management and regulation as the 'force for change', means that networks, (which we argue are an essential mode for adaptation to rapidly changing environments) are poorly understood and suported.

The NHS in the UK is itself following global trends in organisation, moving over the last 30 years from bureaucracy to general management (to get a grip on the power of professionals and bring a stronger management discipline and hierarchy to bear); to markets and the purchaser/provider split (on the assumption that competition drives up quality and brings costs down); through a period of modernisation (quasi-markets and collaboration); to the current mixed model of operations that seems to combine some aspects of competition (procurement mainly), with strong regulation (to protect citizens from poor performance), and collaboration (the focus on devolution is a good example, alongside the move to collaboratives and health systems leadership, and the co-dependence on the third sector to deliver services as funding shrinks).

The other key trend (also global) is the bringing together of management and clinicians in leadership, with high performing health systems taking significant strides in clinical leadership. Some form of 'both and' is emerging, which in itself poses challenges to the dominant ideology of what it is that effects change and innovation. Perhaps the best articulation of this is in the following model of improvement (Berwick et al 2003), which describes two parrallel processes for measurement - one for performance and one for innovation. 


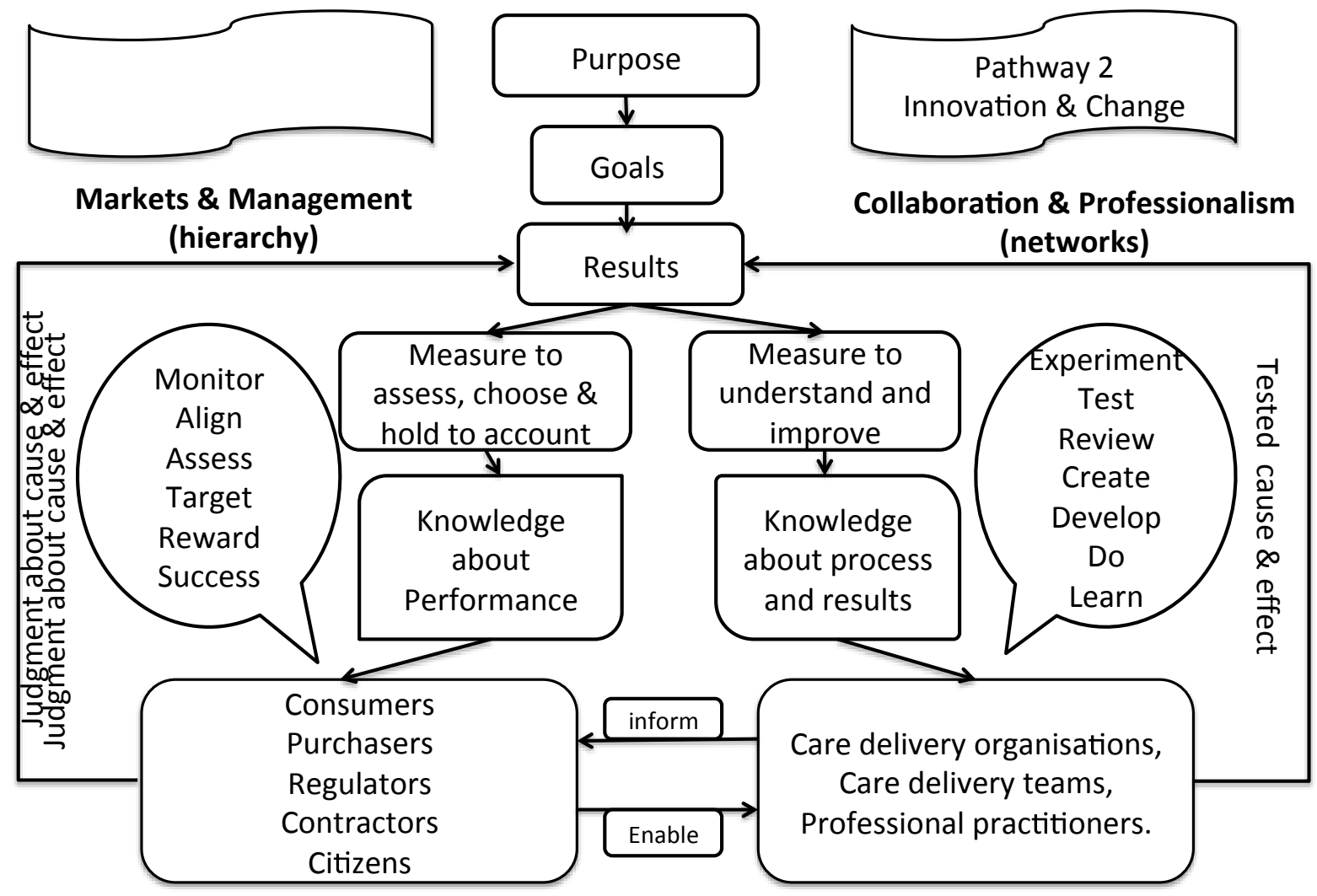

Fig 1: The relationship between quality and performance. Adapted from Berwick, DM, James, $\mathrm{BC}$ and Coye, $\mathrm{M}$. The connections between quality measurement and improvement. Medical Care 2003; 41(1) 30-39 (Jan)

This begins to show some of the tensions between the hierarchial performance management system, and the professional, peer-based innovation system required in any organisation or wider, interdependent system. It demonstrates how both are needed for different and specific purposes and, we argue, not only are the measurement systems different, so are the learning and change systems within each. Interestingly in Intermountain Healthcare, the directorates are now run by a tripartite team of a doctor, nurse and data scientist, the use of data and the discipline of evidence-based decision making has reduced the need for management as we know it in other health systems.

Alongside these trends there is now a recognition globally that markets do not deliver innovation or efficiencies. This, combined with the emerging citizen voice in the design of health services demanding better experience across their whole journey; and the new realisation that collaboration is vital in a cash-strapped economy; means networks are emerging as a way of innovating and enabling change through combined inteligence, resources and effort.

Put together all these factors from policy, to organising, to theories of change, and you can see that networks are vital for the future of health services.

\section{Health Networks}


NHS Leaders are grappling with a range of policy imperatives which have mixed ideology (competition drives up performance; we are all in it together in the Big Society; management gets in the way of clinicians taking responsibility) and which are playing out in a range of conflicting organisational design features. We are seeing a range of models played out in public sector policy in the UK, often comflicing:

- Devolution - with cities being given powers over some or all of health, transport, and housing (local power for local problems)

- Vanguard models of collaboration between acute and primary care, with some level of merger, and across a health system (collaboration and networks)

- Super hospitals (hierarchies)

- Supply chain management through combined procurement, and outsourcing of procurement (markets)

- Self management (individuals owning their issues) and asset-based community development (emergent localism)

- Clinical leadership (Clinical Commissioning Groups) alongside centrally-driven management of clinicians (7 day working)

Alongside these policy changes, the NHS itself is moving beyond the language and models of products and services, reconnecting to its core mission of personalised services to coproduce transformation in people's lives, and to a more collaborative approach to health service improvement.

In a context of reduced resources; the need for innovative solutions to changing health needs; mixed messages in policy; and an emerging new relationship between communities, users and professionals, the NHS needs to be able to:

- coproduce services,

- create space for innovation

- deliver functionality

- work across boundaries 
The increasing challenge of providing services with and to people who have complex needs, often with multiple co-morbidities, leading complicated lives requires health services to work and learn better together and with partners. In fact the research on high performing health systems demonstrates the importance of integration, learning across the system, and engaging citizens in their care. Fig 2. shows the critical themes that have been evident in high performing health systems, and shows the importance of recognising the interdependency between citizens, organisations and professionals.

Fig 2?: Critical Themes in High Performing Systems. Adapted from Baker \& Denis 2011.

\begin{tabular}{|l|l|l|}
\hline Leadership \& Strategy & Organising Design & Improvement Capabilities \\
\hline $\begin{array}{l}\text { Quality and systemic improvement } \\
\text { as a core strategy }\end{array}$ & $\begin{array}{l}\text { Robust primary care teams at } \\
\text { the centre of the delivery } \\
\text { system }\end{array}$ & $\begin{array}{l}\text { Proactive approach to building } \\
\text { skills for quality improvement } \\
\text { across the system }\end{array}$ \\
\hline $\begin{array}{l}\text { Leadership activities embrace } \\
\text { common goals and align activities } \\
\text { throughout the system / network } \\
\text { of care }\end{array}$ & $\begin{array}{l}\text { More effective integration of } \\
\text { care that promotes seamless } \\
\text { transitions }\end{array}$ & $\begin{array}{l}\text { Information as a platform for } \\
\text { guiding improvement }\end{array}$ \\
\hline $\begin{array}{l}\text { Clinical leadership is supported by } \\
\text { professional management }\end{array}$ & $\begin{array}{l}\text { Promoting professional cultures } \\
\text { that support teamwork, } \\
\text { continuous improvement and } \\
\text { patient engagement }\end{array}$ & $\begin{array}{l}\text { Effective learning strategies and } \\
\text { methods to test and scale up } \\
\text { across the system }\end{array}$ \\
\hline $\begin{array}{l}\text { Shared decision-making with } \\
\text { patients and families }\end{array}$ & $\begin{array}{l}\text { Providing an enabling } \\
\text { environment buffering short- } \\
\text { term factors that undermine } \\
\text { success }\end{array}$ & $\begin{array}{l}\text { Engaging patients in the their } \\
\text { care, and in the deign of care }\end{array}$ \\
\hline
\end{tabular}

This need to create new forms of collaborative relations not only requires leaders to be able to lead their own organisation or team, but also to lead with other leaders from other services as peers, in order to collaborate, coordinate, co-design and evolve services that best suit the current environment. This means transcending the traditional hierarchical and markets-based models, and attempting to lead the system as networked entities:

This requires leaders to be able to lead through three different mechanisms - hierarchies (for straightforward performance management and deterministic change), markets (for securing the best supply chain for products) and networks (for interdependent complex services; or to secure innnovations) - making the best use of each in order to effect organisational learning and change (see Chapter Four where this is explained more fully).

"Within hierarchically based organisations [...] the command is the basic instrument of control. In markets, transactions between producers and consumers are governed through price [...] In networks, co-ordination is achieved through mutual informal contact, negotiation and adjustment within a high trust social community or 'clan', such as a profession" (Ferlie, Fitzgerald et al. 2010, p.13).

Powell et al (1999) argue that whilst it is tempting to simplify the NHS journey of organising from bureaucracy, to market, to network: in reality the NHS is operating something of each in a 'quasi' form and always has done 
Perhaps the most well-known networks in the health system in the UK are the Cancer networks. These were really effective early on in their work, at improving and reconfiguring cancer services across the UK, through collaborative structures that utilised data and knowledge sharing that appealed to clinical professionals (Edwards 2002). Sadly the new clinical networks have not always taken onboard the lessons from the early adopters in the cancer networks. The most recogisable and prolific networks over the last 15 years are Collaboratives for quality improvement.

\section{Collaboratives}

Across the NHS there has been a tidal wave of energy around quality improvement. Most of this work is being delivered through managed and learning networks, and through social movement networks. This is a specific niche in health care networks but probably the most dominant form. Collaboratives emerged from the 2000 NHS plan which included a commitment to spread the impact of best practice. De Silva (2014) notes that the organising principle of collaboratives is that "by collaborating and comparing practice, professionals and teams will be motivated to do things differently, which in turn improves patient outcomes and ultimately improves service use and costs" (p3). Improvement collaboratives have generated impact all over the world.

Key lessons from the literature on collaboratives are useful in exploring how networks are different from the dominat experience of 'organising' within health and social care sectors. It suggests that these networks need the following to be effective:

- Consistent leadership that can generate a strategy for improvement and change across the partners

- A distributed membership model including patients and informal care givers

- Realistic expectations of what can be achieved

- Effective learning strategies and a way of buffering the short term factors that limit them

- Time for members / partners to learn and adapt together

- The relinquishing of territory between members/ partners

- Promoting cultures of teamwork, professional review and scrutiny, and patient engagement

- Targeted training and development of champions

- Demonstrated impact

(Mervyn and Amoo 2014; de Silva 2014)

This shows us the great difference between networks and the traditional mode of organising through hierarchies: which is that the core focus of organising in networks is through relationships based on respect, and the principle of 'exchange' or 'reciprocity', which recognises and makes the most of the mutual interdependence of network members, who strive together for a common purpose. Collaboratives have shown us that leading in networks is very different from leading in hierarchies; that networks are fantastic for sharing, learning and spreading innovation when they respect their founding principles of membership and shared power.

You can read more about collaboratives in Chapter 5 Learning and Knowledge Networks.

\section{Why now?}

It seems that the number of NHS networks is on the increase. nhsnetworks currently has over 1000 networks in its membership, with new networks joining all the time. This sense of the increased prevalence of networks in the NHS is caused partly through policy intent and partly 
(in our view) as a side effect of policy. The globalisation of all sectors and the connectedness of our world is also leading to an emerging global phemomena of networks

"In a complex and increasingly connected world, movements and networks are cornerstones of the organizational strategy of the future. They are the best way to bring about massive, scalable, and sustained social impact." Brown 2015.

\section{Policy context}

There appears to be a shift occurring from the formal and often bureaucratic network to the informal, self-managed, self-organised and often self-funded models. Whilst in the early days of networks in health, these network forms where dominated by collaboratives, this has changed, with a much wider ecology of network forms existing now (see chapter 3 on Types of Networks)

There is plenty of literature and theory about structures and strategies in Public Sector Networks (PSNs) and Health Care Networks, however gaps exist in terms of how networks actually improve patient care (Huerta et al., 2006), and the reasons why the current networks have formed. The DoH, (Department of Health., 2000) outlined a modernisation framework (NHS Plan) approximately twelve years ago, which, in a trade for more resources, stipulated that the NHS would reform to meet 21 st century challenges. Collaboration, learning, evidencebased practice, Quality Improvement and diffusion of good practice, were central policy themes in the NHS Plan. Another key theme was networking between different agencies (Ferlie et al., 2010). Since then the UK's 'Transformational Government' white paper and consequent policy reports foresee local authorities evolving from a rigidly structured and hierarchical model to a fluid, dynamic and boundless structure to facilitate multi-agency working, shared services, inter-operability and citizen participation. This has been labelled as a paradigm shift (Ho, 2002). The recent NHS White Paper: 'Equity and Excellence: Liberating the NHS' 2010 provided an overall framework for Clinical Commissioning Groups which it could be argued are suited to a network approach of engaging multiple owners and stakeholders in decision-making. The NHS is moving towards network approaches in other ways: for instance the work on integrating health and social care (Goodwin et al., 2012), and recently the McLean (2011) review of Clinical Networks and Clinical Senates (2011). The climate engendered by these policies entailed the solidification of markets and competition, additional information on health outcomes to support patient choice, and stricter regulation to support choice and competition (Roland and Rosen, 2011). Major disruption related to the control of budgets by CCGs and growing control of public health services by local government was also seen. The lack of a 'system manager' means that there has been an increase in networks to enable shared learning and collaboration. (Malby et al 2013).

More recently The NHS Five Year Forward View (2014) sets out a model of integration and collaboration at odds with the highly competitive market approach of recent policy. The future rests on making the most of people as assets in their own healthcare; aligning skills' not organisations; being accountable together across pathways and organisations in health systems; testing new models and letting local solutions flourish. This approach requires a significant move from hierarchical management and control to networked collaboration and innovation. Perhaps the most likely adopters of network models will be the new Vanguard sites: new collborations between service providers and commissioners in order to secure economies of scale and new approaches to complex health needs through new models of care. 
The free market ideologies underpinning recent reforms, alongside the localism agenda, have perhaps paved the way for networks to develop exponentially, plugging the gaps left by competition in a service that is interdependent. The Five Year Forward View (NHS England 2014) could be seen to capitalise on those networks.

\section{Our views}

A small focus group of organisational development consultants, who are engaged with NHS networks, developed the following hypotheses about why there could be an increase in networks in the NHS/ healthcare system.

- "The NHS is redefining its boundaries and subsequently providing fewer healthcare services. People working at the boundaries of organisations have always sought to network with others in order to solve problems that fall between organisations. This has been done through networking (social networks) and through network structures. The shifting nature of NHS organisational boundaries has generated a bigger gap, which has led to an increase in networks as solutions.

- The interdependence between health service organisations requires partnerships in order to provide personalised services for users. These partnerships in turn spawn networks.

- Society is changing, with more social networking as a core way of behaving in society and an increasingly accepted way of doing work.

- Intractable, complex issues are still evident in health care and networks are a potentially more effective way of working on these issues.

- Networks provide platforms for people who traditionally have less voice / are less visible in hierarchies. They generate power for individuals.

- In the face of uncertainty, networks create a place for being connected, and potentially for support and safety.

- In the face of uncertainty organisations are becoming more centralised internally, and so organisational members are joining networks as a place to be creative, innovative and solve problems.

- Networks have always been part of the health care sector; they are just more visible now."

(Malby B \& Mervyn K 2012 May, p25)

Certainly CEOs of health organisations are expressing concern about how to effect change across the whole patients' experience with a complex interdependency of partners. In a recent survey of CEOs conducted by the Centre for Innovation in Health Management which asked the question:

"What are the puzzles you face as a leader of your organisation and in your health system when looking at health and social care over the next 5 years?"

Issues most consistently highlighted in relation to Chief Executives' role in the system:

- "Working across organisational boundaries: how to achieve system-wide leadership, and how to create a shared vision for services that is focused on the needs of the local population, whilst acknowledging vested interests among the organisations involved;

- Bridging health and social care: how to achieve better working relationships and integrated care across the local health and social care economy;

- Care for vulnerable people: e.g. How to prioritise the care of older people and improve intermediate care services to help people go home;

- Working with communities: how to meaningfully engage patients and communities in designing services, and how to encourage personal responsibility for health; i.e. how do people engage and participate in their own health care, when the 'value' of services 
becomes more of a known quantity and the provider and increasingly the service user must demonstrate cost effective use of limited resources?

- Money: how to maintain financial viability, and ensure regulatory pressures prioritise quality alongside finance;

- Spread and speed of change: how to transform services at a fast pace without compromising engagement with patients and staff, and how to avoid 're-inventing the wheel' both in terms of sharing good practice but also in how organisations complement rather than duplicate each other's work and roles."

(Malby 2015 p 13)

Many of these questions can be answered by exploring the role and impact of networks. In essence: working together for shared purpose in a coordinated way that fosters learning and innovation is key in solving these dilemmas.

However in order to know whether networks for health improvement are being effective, further work needs to be done on the assumption that networks are emerging as a solution to healthcare improvement issues, and what those issues are.

\section{Current state of networks}

Health care networks have emerged to help to address 'wicked' problems (or perhaps are used as a way to avoid solving the tough/challenging issues). These encompass a variety of agencies and professions and provide alternative forms of care configuration and service delivery. Studies have shown that such networks can achieve significant levels of clinical support, authority and legitimacy when supported by an evidence based approach (Ferlie et al., 2010)

There are a plethora of networks operating in the NHS within which is a range of types and scales of network. These different networks are also at different stages of development from early to more mature design stages, and they span different geographies (spheres of control and influence). Add to this the 'permanence' continuum (ad hoc through to sustainable) and we can see that networks are dynamic, multi-dimensional forms with different needs in terms of leadership, membership engagement, design, governance and learning.

However the NHS has some track record in turning new ways of working back into old patterns by:

(a) hijacking new approaches - adopting the language of the new whilst still practising in the old world - turning new ideas back into more traditional, hierarchial models, e.g. managed clinical networks have very little of the 'network approach' about them: they are, in effect, projects rather than networks.

(b) latching on to structural change as the solution to all problems - so adopting the structure without understanding how relationships are organised within that structure. Networks could be seen as the next structural 'fix' .

The NHS uses the term 'networks' to span many different forms of working together. Sometimes these are formal partnerships and projects, and sometimes they are real networks - with all the mess, creativity, and distributed leadership that networks involve. This loose use of the term 'network' further confuses network leaders. Valente (1996) identified two types of network: those that are purpose-designed, funded and imposed by someone in authority (mandated networks), and those that are formed by relationships among clinicians which rest on mutual (often implicit) agreements to participate (natural networks). In fact we find that even within those categories there are multiple network forms. In Chapter Two we give a full overview of networks, and in Chapter 3 we explore the different types of networks in health 
settings. This is not a matter of ideology or organisational snobbery. Knowing what type of organisation you are leading really matters in terms of how you lead, and what predicates success and failure. These are different in partnerships, projects, clubs and networks. For instance projects need a high degree of managing, whereas in networks over-management is 'the kiss of death'. We provide both clarity about what networks are (and are not), the range of networks and how to lead them effectively. Put simply, 'natural' networks are emerging in order to:

- Deliver services together

- Learn together

- Advocate or lobby for change together

$\bullet$

And these different purposes require different information, ways of connecting and learning, and leadership

\section{Who is this book for?}

In our view the wide range of networks in the NHS might not be accessing all the intelligence and evidence about how to lead and design networks fit for purpose. Network leaders can assume that what works in other organisational forms (hierarchies, projects) also works in networks. Our evidence is that leading networks requires a very different approach, more synonomous with systems leadership.

In this book we identify the models of network that work, and how best to utilise the power and potential of networks. We help you be clear about what it takes for networks to 'work'. We also argue that globally organisations are developing strengths in both networks and hierarchies, and that any adaptive organisation needs both; we explore innovation in networks and how to know if your network is effective. Finally we focus on leading in networks, which we believe is the least understood leadership approach.

This book is for anyone curious about and interested in networks, be it someone setting up a network; funders of networks; members of networks; and any NHS leader wanting to lead through multiple forms including networks. 
David Grayson explains the Ko Awatea network

Ko Awatea: Health System Innovation and Improvement

HAERE TAKA MUA, TAKA MURI; KAUA E WHAI

"BE A LEADER, NOT A FOLLOWER"

Ko Awatea is a place-based network designed to generate improvement in health services within one health system - Counties Manukau Health $(\mathrm{CMH})$. It was established as a system level response to creating a high performing health system. It operates to enable improvement and transformation to provide the best and most innovative solutions to healthcare challenges. It supports professional growth, learning and knowledge sharing, innovation and skills development for health system improvement. It is in the mode of Collaboratives -

Ko Awatea has two main offers between and for network members:

(a) Campaigns including the 20,000 days campaign - This campaign, to reduce demand on our hospital by giving back 20,000 well and healthy days to the community

(b) Leadership Academy - offering Education and learning workshops and training programmes on Improvement and leading transformational change.

Ko Awatea was created in 2011 with a mandate to lead an innovative approach to achieving sustainable, high-quality healthcare services at Counties Manukau Health $(\mathrm{CMH})$ and across New Zealand and Asia-Pacific.

Transforming the health system to achieve excellent healthcare in the 21st century context of rising demand for health services and financial constraints requires new ways of thinking and working. Ko Awatea leads and supports healthcare transformation using a collaborative approach to encourage innovation, quality improvement and knowledge transfer. Ko Awatea is also a centre of education dedicated to meeting the needs of students, $\mathrm{CMH}$ staff and visitors through education, leadership and professional development.

Our name, Ko Awatea, means 'first light' - an appropriate name for a centre that is designed to bring together thinking, innovation and action. The name was gifted from tangata whenua, indicative of the value that Maori place on Ko Awatea and its role in $\mathrm{CMH}$.

Our Aim

We have a simple guiding aim in Ko Awatea: to be a hub of education, improvement and innovation to support health systems and public services - foremost to support $\mathrm{CMH}$, but also locally, nationally and internationally.

Our Vision - 'Improving and transforming today'

Ko Awatea is the transformation capability embedded and integrated into our district health board (DHB), our community and our country.

Ko Awatea focuses on transformation and integration through a unique partnership of improvement, innovation, education, research, knowledge management, decision support, and is embedded and partnered in a District Health Board, in South Auckland, in New Zealand, and in Asia Pacific. 


\section{Our Strategic Intent}

Ko Awatea operates across three tiers to achieve its mission and realise its vision: locally, nationally and internationally.

The local level reflects the commitment Ko Awatea has to Counties Manukau Health - Our 'Handle the Jandal' initiative coached and empowered 25 youth leaders to lead and mobilise over 600 Pacific youth to take action to enhance their own mental health and wellbeing, addressing issues around depression, continuing education and parent- youth relationships

The national level, to New Zealand - In our first year, we developed and led a nationwide collaborative of 20 district health boards to reduce the incidence of central-line associated bacteraemia (CLAB) in New Zealand intensive care units. The results showed incidence of CLAB were reduced by 96 per cent.;

The international level, to the Asia-Pacific region - Recent international partnerships include building capability in the area of patient experience and innovation for transformation, as well as designing contextualised, integrated care models and building frameworks for continuing care.

Collaboration through joint ventures and strategic partnerships is key in our approach to working as an improvement and innovation resource across these three tiers. Through its partnerships, Ko Awatea combines the expertise of its internal staff with that of leading international experts in improvement to facilitate practical health system transformation projects underpinned by a proven methodological approach.

Multi-site clinical networks which use data for research and improvement and involve collaborations among groups of patients/families, clinicians, researchers and communities, serve as collaborative laboratories:translating research into practice. Their mode of working is through innovation and discovery, and comparative effectiveness.

The impact of the network is best shown as follows: 


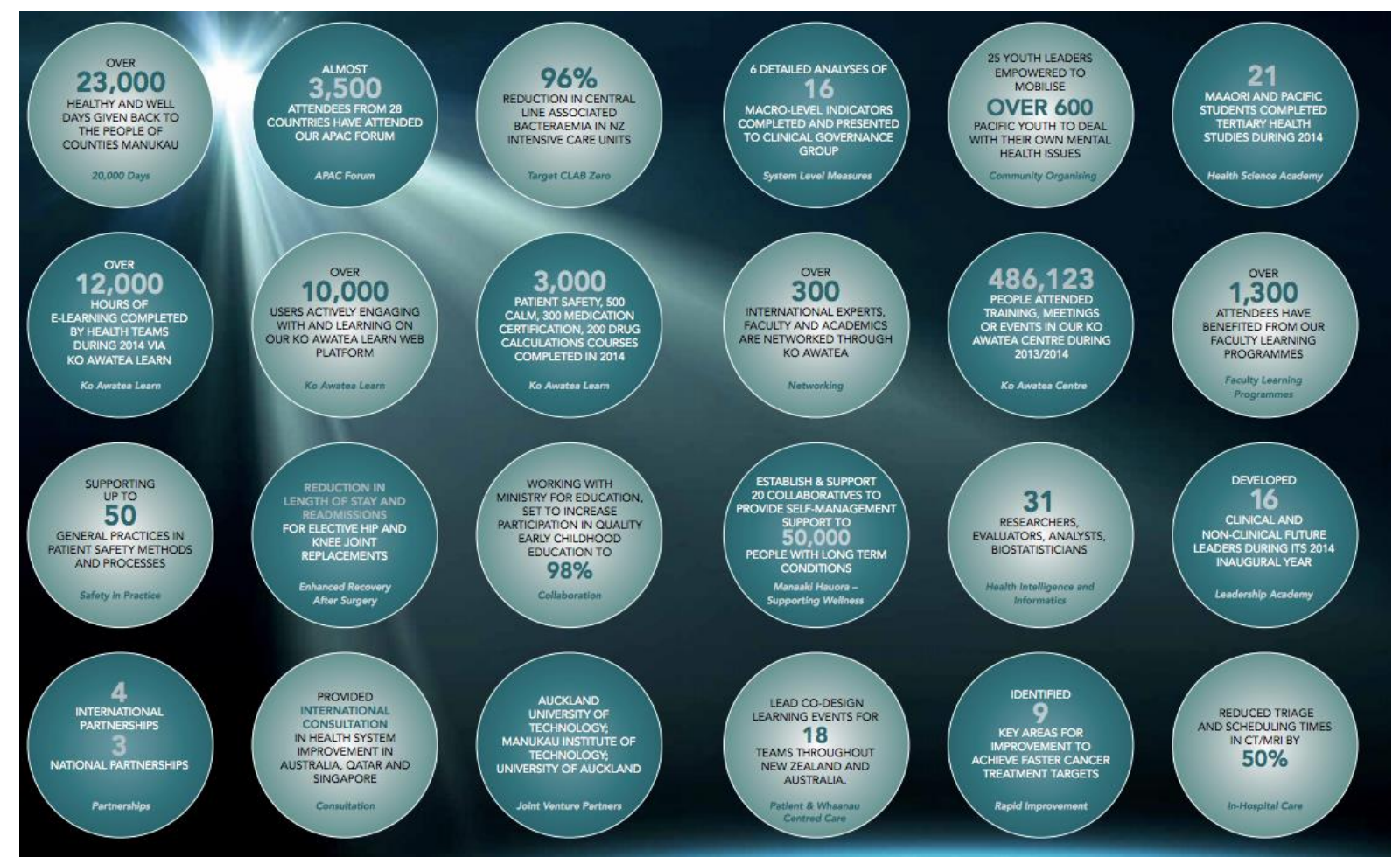

Fig 3 from We are Ko Awatea 2014 p6

David Grayson, Campaign Clinical Lead, identifies the Key lessons from the Ko Awatea experience:

- Senior leadership support

- Alignment with network priorities

- Effective multidisciplinary teams

- Availability of reliable shared data at frequent and regular intervals

- Collaborative structure for learning

- QI methods

- Focus on shared aim

Four years old the Collaborative is leading campaigns, programmes of learning and an international forum in pursuit of system-wide transformation in quality. 


\section{RAMP Of COLLABORATIVES}

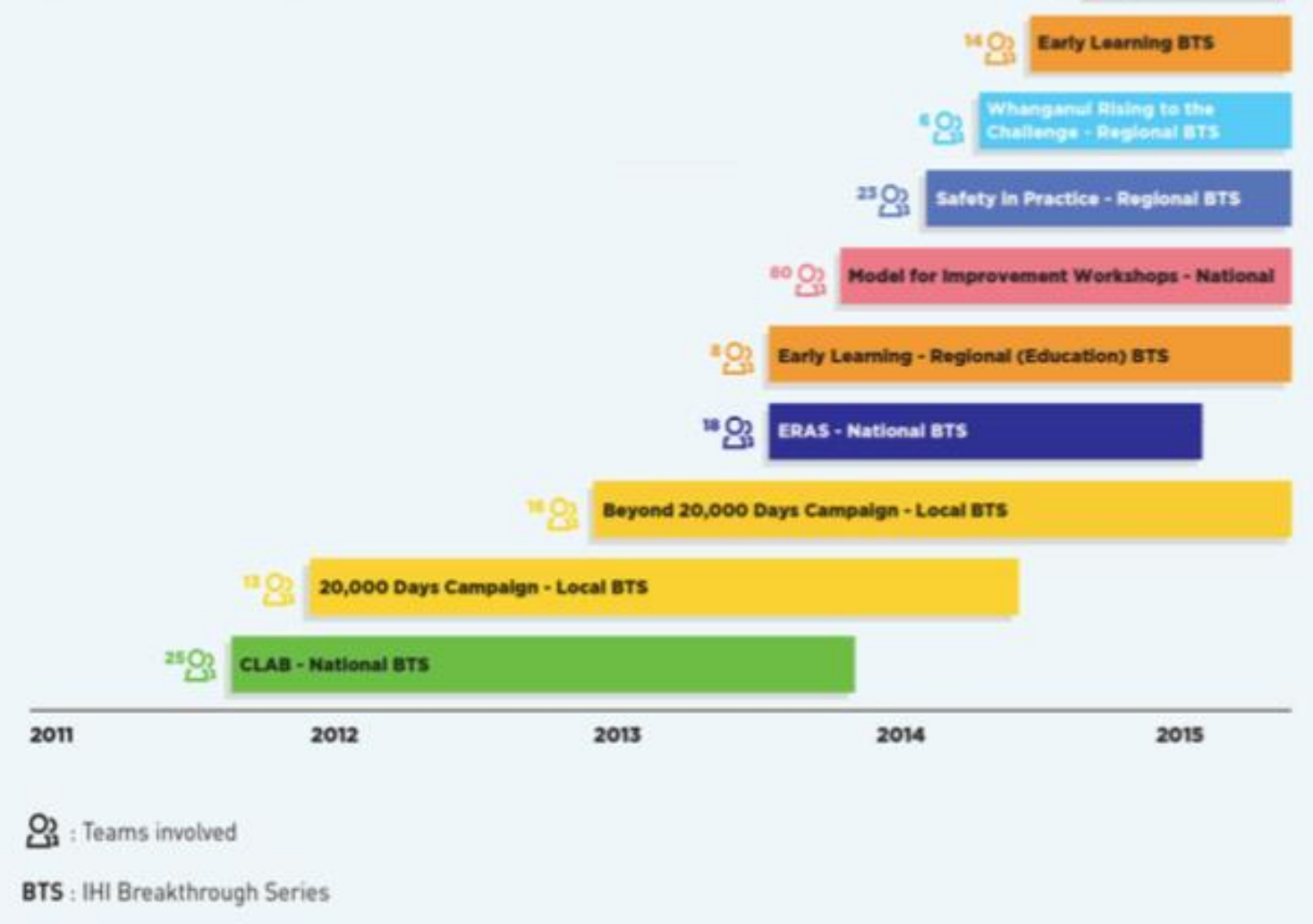

Fig 4: We are Ko Awatea, 2014, p24

http://koawatea.co.nz/ 


\section{References}

Baker G anad JL Denis 2011. A Comparative Study of Three Transformative Healthcare Systems: Lessons for Canada. Candian Foundation for Healthcare Improvement. October

Berwick DM ${ }^{1}$, James B, Coye MJ. 2003. Connections between quality measurement and improvement Med Care. 2003 Jan;41(1 Suppl):I30-8

Brown C 2015 Networks: The New Organizational Strategy. Why nonprofits and funders need to put networks of relationships, instead of transactions and grants, at the core of organizational strategies.Stanford Social Innovation Review blog. Mar. 9, 2015. http://ssir.org/articles/entry/networks_the_new_organizational_strategy

Castells, M. (2011). The rise of the network society: The information age: Economy, society, and culture (Vol. 1). John Wiley \& Sons.

Department of Health. 2000. NHS Plan: A Plan for Investment; A Plan for Reform. London: Department of Health

De Silva D (2014).Improvement Collaboratives in Healthcare. Evidence Scan. The Health Foundation, London.

Edwards, N. (2002). Clinical networks : Advantages include flexibility, strength, speed, and focus on clinical issues. BMJ : British Medical Journal,324(7329), 63.

Ferlie, E., Fitzgerald, L., Mcgivern, G., Dopson, S. \& Exworthy, M. 2010. Networks in health care: A comparative study of their management, impact and performance. School of Management, Royal Holloway University of London.

Goodwin, N., Smith, J., Davies, A., Perry, Rosen, R., Dixon, A., Dixon, J. \& Ham, C. 2012. Integrated care for patients and populations: Improving outcomes by working together. In: 2012, K. F. (ed.) A report to the Department of Health and the NHS Future Forum

Ho, A., Tat-Kei. 2002. Reinventing Local Governments and the E-Government Initiative. Public Administration Review, 62, 434-44

Huerta, T. R., Casbeer, A. \& Vanderplaat, M. 2006. Using networks to enhance health services delivery: perspectives, paradoxes and propositions. Healthcarepapers, 7.

Ko Awatea. 2014 We are Ko Awatea. Health system innovaiton and improvement. Brochure

Malby B \& Mervyn K. 2012. Networks - a briefing paper for The Health Foundation. Centre for Innovation in Health Management, University of Leeds. $P$

Malby B and Mervyn K. 2012. Summary of the literature to inform The Health Foundation Questions. Centre for Innovation in Health Management, May, p 25

Malby R.,Mervyn K, Pirisi L. 2013. How professionals can lead networks in the NHS. International Journal of Leadership in Public Services, The, Vol. 9 Iss: 1/2, pp.47 - 58.

Malby R 2015 Doing' Systems Leadership - Our Experience: Lessons from The Leadership Indaba Centre for Innovation in Health Management, University of Leeds November $\mathrm{p} 13$

Meryn K, Amoo N. 2014. Brief Literature Review on Improvement at Systems Level. Leeds institute for QualityHealthcare.

MCLEAN, K. 2011. Developing clinical senates and networks. In: HEALTH, D. O. (ed.). Medical Director NHS Midlands

NHS England. 2014 The NHS Five Year Forward View.

Powell M, Mohan J, Exworthy M. 1999. Markets, Bureaucracy and Public Management: The NHS: Quasi-market, Quasi-hierarchy and Quasi-network? Public Money \& Management.19(4):15.

Roland, M. \& Rosen, R. 2011. English NHS embarks on controversial and risky market-style reforms in health care. New England Journal of Medicine, 364, 1360-1366 
Valente TW. Social network thresholds in the diffusion of innovations. Social Networks 1996;18:69-89 